\title{
Article
}

\section{'It's better than daytime television': questioning the socio-spatial impacts of massage parlours on residential communities}

\author{
Cooper, E
}

Available at http://clok.uclan.ac.uk/14694/

Cooper, E ORCID: 0000-0003-1013-2755 (2016) 'It's better than daytime television': questioning the socio-spatial impacts of massage parlours on residential communities. Sexualities, 19 (5-6). pp. 547-566. ISSN 1363-4607

It is advisable to refer to the publisher's version if you intend to cite from the work. http://dx.doi.org/10.1177/1363460715616949

For more information about UCLan's research in this area go to http://www.uclan.ac.uk/researchgroups/ and search for <name of research Group>.

For information about Research generally at UCLan please go to http://www.uclan.ac.uk/research/

All outputs in CLoK are protected by Intellectual Property Rights law, including Copyright law. Copyright, IPR and Moral Rights for the works on this site are retained by the individual authors and/or other copyright owners. Terms and conditions for use of this material are defined in the policies page. 


\title{
"It's better than daytime television": questioning the socio-spatial impacts of massage parlours on residential communities'
}

\begin{abstract}
It has been shown that street sex work is problematic for some communities, but there is less evidence of the effects of brothels. Emerging research also suggests that impact discourses outlined by residential communities and in regulatory policies should be critiqued, because they are often based on minority community voices, and limited tangible evidence is used to masquerade wider moral viewpoints about the place of sex work. Using a study of residents living in close proximity to brothels in Blackpool, this paper argues that impact is socially and spatially fluid. Impact needs to be evaluated in a more nuanced manner, which is considerate of the heterogeneity of (even one type of) sex work, and the community in question. Brothels in Blackpool had a variety of roles in the everyday socio-spatial fabric; thus also questioning the common assumption that sex work only impacts negatively on residential communities.
\end{abstract}

Key words: Sex work, residential communities, impact, stigma, order 


\section{Introduction}

In both academic and non-academic worlds, the sex industry, particularly prostitution, is frequently contested. The conflicts and stigmatization generate multi-faceted social and spatial exclusion, and the othering of individuals in the profession. To what extent prostitution offends has therefore been significant in the formation of both legislative and social norms and orders, and is directly linked to its impacts on communities. Impacts cited - particularly for on-street sex work - are often framed in moral or nuisance discourses (Kantola and Squires, 2004), are laden with dirt and disgust rhetoric, and are multi-spatial; prostitution not only offends and causes disorder for the community at a local scale, but it also corrupts the wider reputation of the area in question (Crofts, 2010; Hubbard and Sanders, 2003; Hubbard et al., 2013), such as the (perceived) lowering of house prices or rising crime rates. These are cited in policy documents, such as the Home Office (2004) 'Paying the Price' consultation, as well as media reports (O Neill et al., 2008).

Prostitution sits uncomfortably on the boundary of several binary debates - pure (normal) and impure (abnormal) sex; the fallen woman or the sexual fiend; legal or illegal etc - and adopts a similarly liminal and ambiguous position in socio-spatial worlds. This positioning is represented in legal frameworks, with the sale of sex being allowed in UK law, but the practise of doing so being made very difficult. The shifting of societal viewpoints has since begun to lean more towards the desire to criminalize the client (Sanders, 2006; Sanders and Soothill, 2011), but the legacy of prostitutes as being 'noxious neighbours' (Hubbard et al., 2013) but a 'necessary evil' (Spector, 2006), and that sexual encounters should be conducted privately (Atkins and Laing, 
2012), has prevailed. Off-street sex work, such as brothels, offer an important contribution to this theorization, as sex workers/clients are inherently 'in-place'; in a building that conceals the actions and people, but is used for the exchange of sexual services for money.

Despite the suggested polluting characteristics of sex work, evidence of impacts on residential communities is limited (Kingston, 2013) and often pertains to perceived secondary (unsubstantiated) effects (Hubbard et al., 2013; Weitzer, 2005). It is argued that impacts reported usually derive from louder members of the community with particular agendas (Brooks-Gordon, 2006) and thus the more mundane experiences of these spaces are overlooked. Attempts to purify space by zoning or expunging prostitution (Edwards, 2010; Hubbard, 1997; Mathieu, 2011; Matthews, 1993; Sanchez, 2004) also often refer to on-street sex workers: the impacts of indoor sex work are under-represented (Sanders, 2008). Several studies argue offstreet sex work (especially establishments with more than one worker) is safer in some ways, such as assistance with violent clients (Hubbard and Prior, 2013; Krusi et al., 2012). Furthermore, given that off-street markets have been less vehemently opposed by residential communities - and often have longevity in some localities, suggesting tolerance (Kingston, 2013; Soothill, 2004) - it is therefore important to examine their role in everyday geographies; to explore whether their liminality and ambiguity provide the balance for residential communities.

Drawing from research with communities in close proximity to several brothels in Blackpool, this paper seeks to provide a timely contribution to these research gaps. The importance of understanding the role of community complexity and heterogeneity in evaluating impact, 
alongside the more mundane, everyday geographies of living and working in close proximity to spaces of sex work, will therefore be evaluated.

The paper will argue that impact needs to be understood as a fluid concept; one that fluctuates depending on what community norms/orders are constraining or enabling a resident at particular socio-spatial scales, and one that does not necessarily fall into binary categories often associated with constructions of sex work. To conclude, the paper argues that homogeneous assumptions about sex work and community in evaluating impact are unhelpful for all who use the space.

\section{A note on brothels and regulation}

Brothels possess a dubious legality in England: managing and profiting from a brothel (premises with more than one sex worker offering sexual services) is illegal according to the Sexual Offences Act (1956), but if sex is negotiated between a single sex worker and client within a premises and the owner does not directly profit, then this is legal. There is variation to the licensing and policing system across the UK; some local authorities license establishments to sell massage services (Sanders, 2005), and others do not, and the terminology describing such premises also varies locally. The Policing and Crime Act (2009) made closures easier, allowing the police to seek a court order prohibiting access to premises associated with certain prostitution or pornography-related offences. Relatively few prosecutions are made in relation to brothel-keeping (Soothill and Sanders, 2011), indicating that the 'turn a blind eye(...)until too many people complain' approach adopted by gatekeepers in Blackpool (Cooper, 2014) is replicated elsewhere. 
Brothels typically embrace an ambiguous method of advertising, operating under a euphemism or guise (Ibbitson, 2002) such as massage parlour/sauna (although not all massage parlours/saunas provide sexual services): rarely outwardly stating that sexual services are available on the exterior of the building, but sometimes with suggestive imagery/aesthetics and/or a website alluding to these. Brothels vary in size, organizational structure, and sex worker demographic. In Blackpool, all participants mostly described the premises as massage parlours and so the rest of the paper will use this terminology.

\section{The community sex factor: problems with impact discourses}

Given that much research has reported that communities desire to expunge or displace (especially on-street) prostitution, it would be valid to assume that its effects are homogeneously negative. Kantola and Squires (2004) frame impacts into nuisance or moral discourses, with environmental nuisance (more associated with on-street sex work) including litter and noise (Benson and Matthews, 2000), fear of going out after dark, or being mistaken for sex workers/clients (Kingston, 2013; O’Neill et al., 2008), and criminality ranging from public urination to sexual crimes (Hubbard et al., 2013). Historical fears of contracting venereal disease from discarded condoms in public spaces, or clients infecting non-sex worker populations (Whittaker and Hart, 1996) still pervade certain stereotypes about sex work now (Desyllas, 2013). Moral discourses (more associated with off-street sex work) surround the corruption of the community (especially children) by witnessing soliciting, or the decay of 'family-orientated' neighbourhoods (Prior and Crofts, 2012). Typical tactics applied by 
residents to indoor workers in Britain mainly include 'naming and shaming' individuals to agencies such as the media and the police (Sanders, 2005).

Law and regulatory policy, such as the Street Offences Act (1959) and Home Office Coordinated Strategy for Prostitution (2006) have also framed sex work as a blight on communities. Motivations for national policies and local interventions, such as the 2013 brothel raids in Soho (The Guardian, 2013), are often in response to fears around sex trafficking; thus creating the 'rescue industry' (Agustin, 2007), which repeatedly relies on trafficking mythologies and unsubstantiated claims (Weitzer, 2007). This is especially true with indoor sex work (Weitzer, 2007), despite the fact that the majority of off-street sex premises are not involved in extreme exploitation or organized crime (Sanders, 2007). The pervasive conflation of sex work with trafficking is reproduced in sex work policy and media reports (The Guardian, 2009), creates blurred distinctions between coerced and consensual work (Jana et al., 2013), and reinforces the argument that sex work policy ignores the complexity of sex work markets (Sanders, 2007).

There are many problems with impact discourses surrounding sex work; the first of which relates to the lack of in-depth research conducted with communities that live and work in spaces of sex work (Kingston, 2013). Communities and their socio-spatial boundaries are diverse, and problematic simplifications or ambiguities about the impacts of sex work are put forward as being representative of the everyday picture. Examples of these problems are: a lack of a diverse community voice being examined, real versus perceived impacts, and homogeneously negative depictions of the presence of sex work. 
O'Neill et al., (2008), in their research on community tolerance to on-street sex work in England and Wales, identify several responses, ranging from sympathy with sex workers to the desire to exclude them. However, dominant community voices obscured more conciliatory views (also see Sagar and Jones, 2012). Brooks-Gordon (2006: 62) included an apt quote from a police officer; it is the 'squeaky wheel getting the oil' and therefore regulatory policy is skewed, because community representation is unbalanced. The absence of sex worker voices is also noted by several of the scholars cited here (eg Kingston, 2013): they are rarely consulted as community members in local authority consultations.

Hubbard et al., (2013) also outline tensions between real and perceived impacts from research with residents in New South Wales. Those who lived closer to commercial sex premises reported lesser or similar nuisance to those living two or more blocks away, whereas less tangible impacts (such as the decay of community morality) spread across a wider area; indicating that increased proximity to the buildings themselves is not what necessarily offends with indoor sex work in the same way as on-street sex work.

Crofts (2010) also likens the desire of residents in New South Wales to remove brothels to fear of attracting criminality or encountering clients/sex workers rather than tangible harms that these interactions will/have caused. Stereotyping of clients and sex workers as criminally ambiguous leads residents to assume that sex work has negative impacts that are rarely realized (Hubbard et al., 2013), which the media perpetuates (O’Neill et al., 2008; The Guardian, 2009). News articles surrounding community opposition to current or new massage parlours often feature discussion of their (inappropriate) proximity to other buildings, such as 
churches/schools/other businesses (Lancashire Telegraph, 2013; Liverpool Echo, 2014). The preoccupation with who can (or should be able to) see sex work, and how its presence makes the locality socio-spatially 'look' (eg concerns around reputation) is widely noted in literature about sex work regulation (Hubbard and Prior, 2012). However, the ability for off-street establishments to be ambiguous in their advertising/appearance, possessing some similar features to other shops/buildings in the streetscape and conforming to local norms, also potentially generates tacit acceptance by communities (Kingston, 2013).

Moreover, positive impacts of sex work on communities are rarely, if ever, mentioned. Examples include: increased economic profits for the surrounding localities (Brents and Sanders, 2010), increased lighting in otherwise dark and lonely areas heightening feelings of safety, and reducing crime numbers due to sex workers reporting 'dodgy punters' (Kingston, 2013).

\section{Methods}

To reveal a diverse community voice and capture the everyday experiences of sex work spaces, this research involved semi-structured interviews with various community members in Blackpool: 53 local residents/workers in local businesses, 3 female parlour sex workers (Cindy was also the manager of a parlour), 3 Council officers and 3 police officers. Participant observation of 2 residential areas with massage parlours (on and around Cookson Street and Central Drive) was also done over the course of 1 year (2011-2012). Only female sex workers 
were working in the parlours during the time of study in these two areas. Sex worker interviewees were all white, from the UK originally and lived locally. Participants were mostly recruited from participant observation, and subsequent snowballing techniques. Individual interviews were combined with group interviews, so as to examine the factors in social interaction that influence individual assumptions (Brooks-Gordon, 2006). Residents were predominantly white (2 respondents were black), of varying ages and employment statuses, religious backgrounds and residential circumstances.

As responses varied little when comparing different socio-economic backgrounds between participants in this case study - the spectrum and fluidity of impacts were evident from all respondents - this is not the focus of the paper.

Participant observation involved experiencing the location as a resident would at leisure, so I walked/drove through the areas, shopped, went into businesses, had coffee, chatted with residents etc. It is essential to develop strategies that attempt to reveal diversity within each sector of the industry (Shaver, 2005): observations highlighted several differences between parlours and their socio-spatial visibility. 


\section{Study site: Blackpool}

Blackpool is a seaside town in the North-West of England, with a population of approximately 142,000 (Lancashire County Council, 2012). Several wards in Blackpool have high levels of deprivation, including the two where Cookson Street and Central Drive are located (Talbot and Bloomfield respectively). Both wards are predominately white (above $94 \%$ of the population) and have similar age and socio-economic profiles - although the Bloomfield ward unemployment figure was slightly higher (Blackpool Council, 2011).

Blackpool's sexual leisure establishments are diverse, including: on-street prostitution, brothels, private flats with independent sex workers, lap dancing bars, sex shops and swingers' hotels. During the research, there were five massage parlours on Cookson Street and four on the three adjoining streets (some of which had been present for several years), and three massage parlours on Central Drive. These areas are on the outskirts of Blackpool's central business district and contain a variety of businesses and residences. Parlours did not vary substantially in size, but did in appearance and opening hours; for example one in the Cookson Street area opens at 10am and closes at $10 \mathrm{pm}$ every night, whereas others are open 24 hours. Figures 1 and 2 show Cookson Street and Central Drive respectively: 
Figure 1 - Cookson Street. Note 'Tabu' which is one of the parlours.

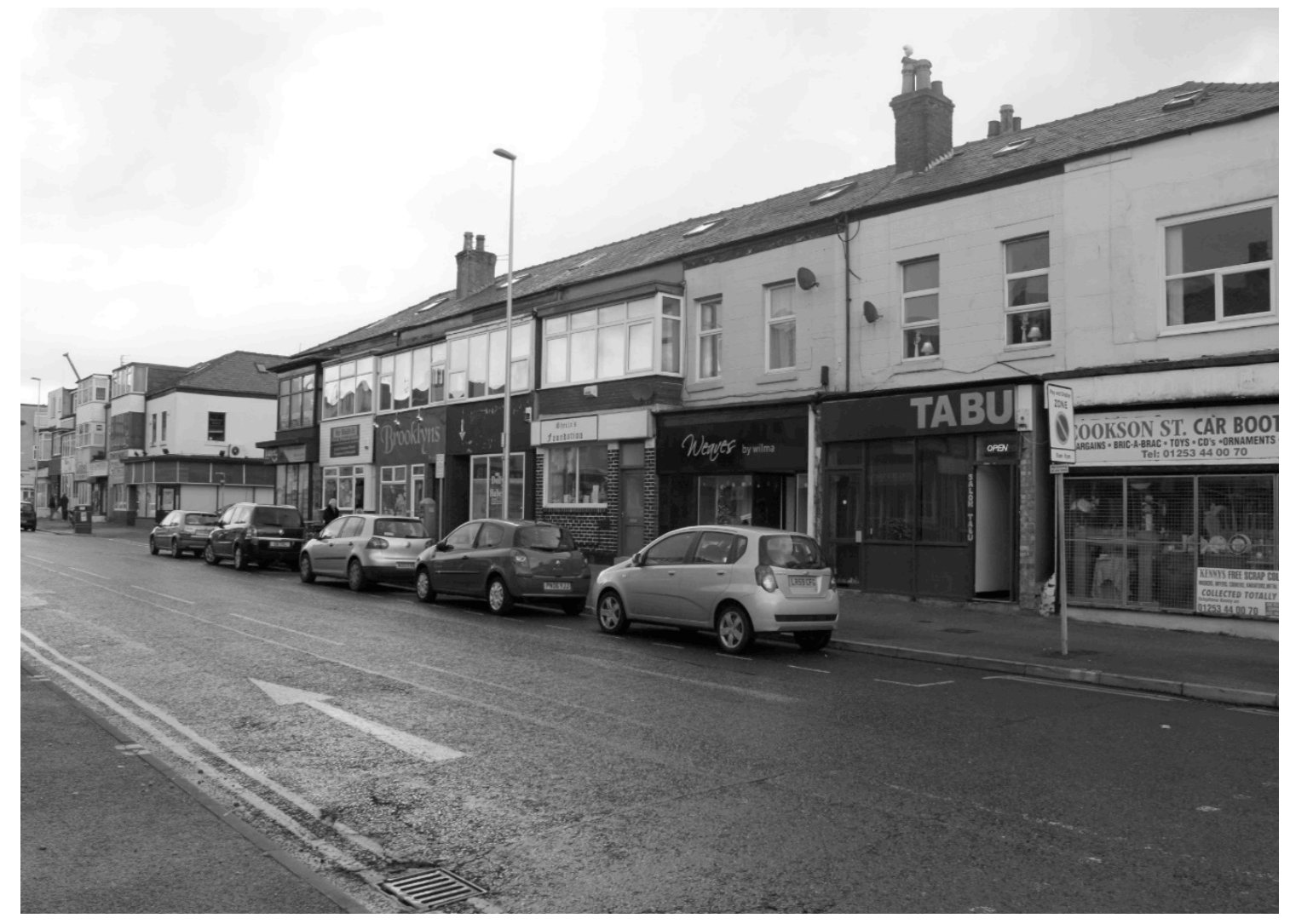


Figure 2 - Central Drive. Parlours cannot be easily seen in street view - these are typically located above other shops, with entrances on the streets behind

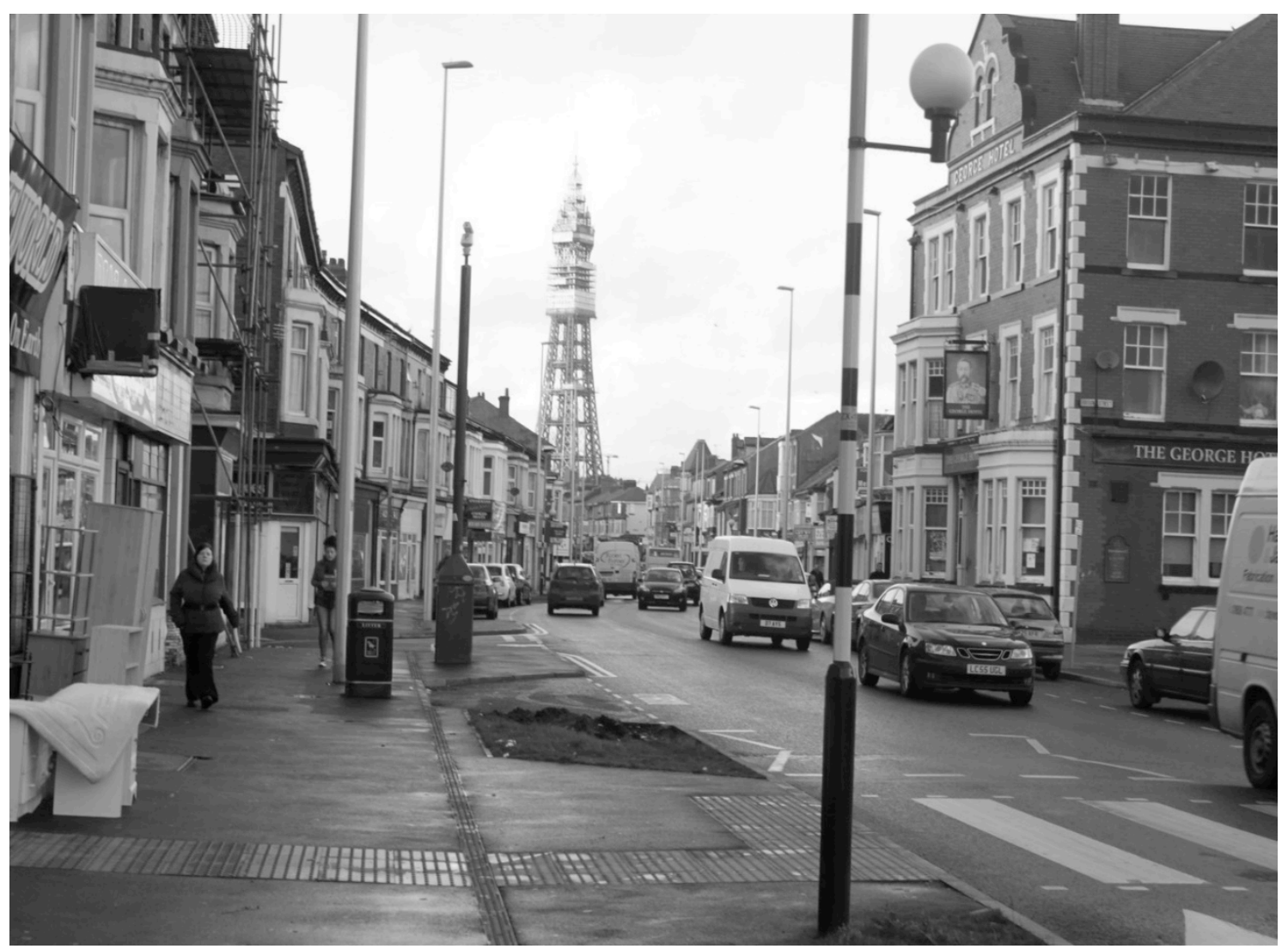

Council campaigns and local media depict a confusing picture of how massage parlours are regulated in Blackpool, largely because political campaigns about what to do with the sex industry fluctuate. Over the course of this research and my previous study in 2008 (Cooper, 2008), Blackpool Council changed leadership (Conservative-Labour), with the earlier years representing more clamping-down periods towards Blackpool's sex industry. Blackpool Gazette documents activity associated with the sex industry fairly regularly, including parlour 
raids and community complaints, and often contains dirt/disgust rhetoric (Blackpool Gazette, 2013). Comments from residents underneath articles suggest confusion surrounding the legal position of the massage parlours, and contain assumptions about trafficking and crime levels in these areas.

The regulation of massage parlours is also inconsistent. Blackpool, as described by a Council Officer (2011), has a 'virtually zero tolerance' approach, but regulation needs to 'maintain a balancing act' so as to 'protect all concerned and not just displace sex workers onto the streets'. If a parlour is 'well-managed' and 'discreet' then it is 'tolerated', but if it 'causes problems' (such as excessive noise) then it is acted upon. What discreet means, however, is subjective, and fluctuated in Blackpool; one example is that parlours were told to change coloured neon lights to white following 'clamp-downs' by the Council, before colours being allowed to trickle in again. Clamp-down periods by local authorities often place disorder into categories of visibility (Prior et al., 2013), with a prominent focus on policing the parlours' vibrancy (especially colour) and sexually suggestive imagery in the streetscape; deemed by scholars as the 'optical governance' of sex work spaces (Hubbard and Prior, 2012). Premises are monitored regularly (usually monthly) and a nominated police officer is responsible for the parlours directly. 


\section{The socio-spatial fluidity of impact}

The use of the localized lens outlined above is important when evaluating impact for several reasons. Firstly, this approach captured the more mundane, everyday lived experiences of residential communities with sex work premises, as opposed to reactionary complaints. Secondly, the comparison of two areas with multiple massage parlours allowed the heterogeneity of the indoor market to be documented. Thirdly, the role of the multi-scaled (Hoggett, 1997) - and sometimes conflicting - nature of community norms and orders in shaping individual perceptions of the parlour impacts was revealed: place-based (Smith, 2000), such as the streets, the work space and Blackpool's leisure identity; relationship-based, such as the boss and employee or the husband and wife; the more imagined (Strysick, 2002) wider societal stigmatization of sex work more generally; and the navigation of individual perceptions in and through these. The blurring and porousness of boundaries between various community ties became further complicated by the dichotomous desire/disgust attachments attributed to sex work (Hubbard, 2000; Sibley, 1995).

It was found that massage parlours are kept in a liminal socio-spatial position due to conflicted (dis)loyalties to various community orders, and have a variety of roles in everyday life. Subsequently, relationships between residents and parlours/sex workers are complex and impacts of their presence fluctuate. This fluidity was evident from all residents, even those who demonstrated the most vehement moral or religious agendas (members of the Salvation Army for example). Fluctuations will be illustrated by three themes: the geography of stigma; the 
subsequent socio-spatial behaviours of residents; and tensions between real and perceived impacts.

\section{The geography of stigma}

While underlying stigma - often based on stereotypes, and communicated in the form of dirt/disgust rhetoric - was at least thinly present in most depictions of the parlours, this was deployed in space with varying degrees of subtlety. These degrees vary between the two streets (Box 1), between the parlours (their visibility) (Box 2), and the extent to which the parlour is interacted with by residents (Box 3).

Box 1 - Examples of differences between Central Drive and Cookson Street descriptions

'The (women) on Central Drive are dirrrty' (Matt, 24: Worker in both areas)

"Have you seen the state of the prossies?!! OMG!! One of'em has got piano teeth and the other one swishes an ulcerated leg around full of pus!!!!” (Anonymous Resident-Comment on Blackpool Gazette website, 2013, about on-street prostitution on Central Drive)

'Yeah but I'm wary of calling the women in the parlours prostitutes as they aren't on the street'. (Hayley, 26: Resident by Cookson Street)

'But the prostitution here is behind closed doors, whereas Central Drive...it's less contained'. (Lindsey: 35: Resident on street adjacent to Cookson Street)

Differences between area descriptions were for several reasons. Firstly, Central Drive participants discussed lesser community spirit than Cookson Street and less interaction with sex workers. Cindy (sex worker/parlour manager: Central Drive) reinforced this; she 'gets the 
impression they (residents) aren't bothered by them', and they are 'left to their own devices'. This lack of interaction coincided with slightly more extreme dirt/disgust lexical choice used by residents in the Central Drive area on occasion, such as 'prossies' and 'dirrrty'. Residents were more willing to extend their everyday leisure time on Cookson Street; the locality of everyday spaces and movements was much more socio-spatially constrained in Central Drive.

Secondly, this spatial distinction also often came when referring to on-street sex workers on Central Drive compared with sex workers in the parlours. Central Drive is known for on-street prostitution, whereas Cookson Street is not; thus it is deemed a more complex immoral landscape (Symanski, 1981). The suggestion that social hierarchies are present (Hubbard and Sanders, 2003), with sex work 'behind closed doors' being more acceptable, is evident, alongside questioning the use of 'prostitute' when referring to parlour workers.

Thirdly, the heterogeneity of the parlours' appearance and levels of interaction in the community have an influence on perceptions. In the Cookson Street area, parlours usually have a more confident, on-street presence with visible entrances and more lighting, whereas Central Drive parlours are usually above another business with an entrance away from the main thoroughfare. During observation, I noted that the 24-hour presence of the more vibrantly-lit parlours on Cookson Street made the area feel more inclusive than the hidden-away entrances of Central Drive. 
Box 2 - Parlour heterogeneity (socio-spatial presence)

'It's a bit creepy though having what looks like barbed wire outside. Makes me think of a prison' (Speaking about Tabu, Cookson Street.) (Hayley, 26: Resident by Cookson Street)

'I think the Natalie's Sauna one looks more like a business with the opening hours on the side (...) as opposed to Tabu with the barbed wire and blacked out window. It sends a message that the women are being looked after (Paul, 58: R. by Cookson Street)

I've known customers to walk in there and think it was a Thai restaurant. There needs to be a balance between discreetly suggesting what they offer and making it clear that they are selling sex' (Pat, 64: Worker on street adjacent to Cookson Street)

Parlours vary in their outward appearance - some displayed cartoon images of women and signs such as 'hello boys', and others just an 'open' sign. As depicted in comment one, Box 2, certain decoration reinforced stereotypical conflations of trafficking with sex work, and imprisoned sex workers. Although it was discussed by police officers and sex workers interviewed that not all workers in the parlours were local (Laura - sex worker, Central Drive area - knew two Polish workers in another parlour close by), most were from this sample, and also lived locally. One police officer confirmed that Blackpool does not have a particular problem with trafficking in the parlours. Residents therefore contradicted themselves; many who said/implied 'all the women are trafficked from abroad' only ever discussed English workers when interviewed, and did not report any examples of exploitation or abuse from friendships built with sex workers.

Interestingly, parlours that are more confident and effectively balance being a sex work business with retaining discreetness are more tolerated (also depicted by Box 1 earlier). Passers-by are 
aware of what they are but the business validity 'sends a message that the women are being looked after' and prevents mistakes being made about the business use (comment 3, Box 2). This also highlights a potential tension in the (optical) governance of the parlours, between what the local authorities typically want to 'cleanse' (eg turning vibrant colours to white or removing sexually-orientated lamps from view) and what residents feel should be visible in their streetscape. This parlour heterogeneity, and the distinctions between the two streets, are important when understanding relations between sex work and communities; the visibility and style of advertisement (and its rapid fluctuation in many cases) creates fluctuation in perception.

Finally, fluidity in language was evident within all descriptions. Box 3 is a case study of one interview whereby sex worker description varied frequently:

Box 3 - Extent to which a parlour/sex work is interacted with

'Oh yeah I know her, Lynn (sex worker), she talks to me when she puts the bins out'

'They dress provocatively and nobody wants to see women in bikinis answering the door constantly'

'I do see the prostitutes and think, like I said before, bonny bonny girl'

Pat, 64: Worker on street adjacent to Cookson Street

The extent to which a sex worker participates, or is allowed to participate, in the community has an influence on the impact discourse. Pat fluctuates between calling the sex worker by name when outlining a mundane interaction such as putting bins out together, but then 'prostitute', 'bonny girl' and 'women in bikinis' were used when describing the same sex worker and others 
when she sees them in the window of the parlour. The significance of the spatial distinction correlating with the lexical choice is also evident: once Lynn crosses the threshold of the parlour, the language changes and (she) becomes stripped of her name, and her adult identity.

\section{Fluidity of socio-spatial behaviours}

This notion of boundary demarcation/blurring extends from the impacts on verbal descriptions into socio-spatial behaviour. Reminiscent of Smith's (2000) description of a community as a contested site, with moralities being (re)made across space, participants outlined different behaviours depending on the context. These behaviours varied in severity and visibility (Box 4), and fluctuated depending on the community norms/orders influencing a person (Boxes 5-6).

Box 4 - The visibility of stigma and stigma behaviours

'Oh I'll say something to them if they're pissing me off. Standing in the doorways is not acceptable in daylight' (Jim, 52: Worker on Cookson Street)

'She used to watch them go in and shout 'you dirty old bastard' (Pat, 64: Worker on street adjacent to Cookson Street)

'I admit I do glare sometimes, and I spend longer peering into windows of shops next door' (Doug, 48: Worker on Central Drive)

The visibility of stigma behaviours also had a spatial disparity. Cookson Street areas not only involved excessive (unofficial) 'neighbourhood watch' duties, but also confrontation and profanity (comments 1 and 2, Box 4). In comparison, Central Drive areas evoked more of a 
muted response during everyday interaction, with participants feeling far less comfortable voicing opinions or utilizing more obvious behaviours to express how they feel about the areas; preferring to 'glare' for example. The watching is also indicative of the desire/disgust boundary fluctuation (Hubbard, 2000) often associated with spaces of sex work and deviance.

The contradiction to this, however, was during a 'Police and Communities Together' meeting, which are monthly or quarterly events set up for individual wards of Blackpool. Residents are invited to share their views about neighbourhood issues, and representatives from the police and Blackpool Council usually attend. Cindy and Laura (sex workers: Central Drive area) stated that, during one meeting, it was expressly desired by another resident that they were excluded (they refused) as the 'meeting was partially about them'. This again brings in the notion of spatial distinctions regarding acceptability; Cindy believed residents 'aren't bothered by them', yet during this particular meeting they were deemed out of place.

I argue this fluctuation happens because of two other reasons: one, the fact that the more prominent presence of the parlours in the Cookson Street area depicts more of a legitimacy (and therefore sex workers are seen as less vulnerable and can be confronted); and two, that the more cohesive community feel allows residents to feel more comfortable reporting something that is irritating them in everyday interactions. Removing the spatial distinction, however, and these quotes still demonstrate a spectrum of acceptability, which has a temporal complexity within individuals as well as between streets. Jim, who stated that he will 'say something if they are pissing (him) off' also states that he generally 'isn't bothered' by the parlours. All quotes demonstrate an ambivalence or a liminal positioning, and all are situated in the community 
norms being applied to the individual and the surrounding area at any given time or space: in Jim's case, daylight is the indicator for what is acceptable (visible) behaviour on this street and what determines the impact of 'pissing (him) off'. Furthermore, during this interview, Jim was also 'standing in the shop doorway in daylight' having a cigarette; indicating a double standard to the governance of sex worker behaviour.

Examining relations at a more localized scale also reveals complexity within everyday relationships, with individuals attempting to adhere to multiple norms/orders present. The example below is of an employer battling with her own feelings towards the parlours versus her boss':

Box 5 - Employee and boss relationships

'Leanne (sex worker) comes into our shop for a chat if there's been a problem with anything'.

'We can't usually talk about the parlour when she (her boss) is in as she doesn't like them. We have to whisper in the back room or rush out and speak to them if we need to, like when we needed to tell her (the sex worker) that someone had scratched her car'

'We do watch what goes on, you can't help it. The window is just like a flatscreen and you can hide behind the counter and pretend to look for something if you get seen gawping by one of our customers'.

Mandy, 53 (Worker on street adjacent to Cookson Street)

Mandy noted that her socio-spatial interaction with/about the parlours varied depending on if her boss was in or not (who had negative views about prostitution). Mandy outlined her 
apprehension of reporting sex workers for offences such as getting changed with the curtains open (reinforcing the importance of the visual line of sight and the acceptability of sex worker bodies being in view while in the parlour) - as her boss occasionally requests - as she was reticent to put the women in vulnerable positions, and did not want to jeopardize friendships. On most days, Mandy described watching the parlours through the 'flatscreen window' that her desk faces.

It is evident that these differing behaviours document the various community orders that are conflicting and both constrain and enable Mandy's behaviour in this context: the 'hiding behind the counter' to mask she is looking, but still 'rushing' across to inform the sex worker about her car (due to friendships built and the neighbourly duty felt) so that nobody will see, is reminiscent of the boss' feelings towards the parlours and the socio-spatial constraints of the workplace control. This public behaviour could be misconstrued by others as Mandy's own more private perceptions, rather than adhering to her boss'; thus highlighting a tension between perception and behaviour. These tensions are situated in the wider societal stigmatization of sex work more generally, and therefore the multi-scaled, complex nature of community is reinforced here. 
Jim (Box 6) also highlights a role of the parlours as being an everyday spectacle:

Box 6 - Temporal fluidity and pockets of orders

'It's different every day' - 'I'll strategically stand with my cigarette so I can see everything'

'They aren't much bother to me, except when I'm having to give evidence in court about them *laughs* but that wasn't anything to do with the prostitution per se'

'Like it or not the parlours are on the same street as us so we have all got to get along. Not everyone agrees mind and you have to empathies - they are your customers after all'

(Jim, 52: Worker on Cookson Street)

'It's different every day' is especially revealing of a temporal fluidity to perceptions, and a sense that parlours keep the everyday work/home routine interesting. Research surrounding on-street sex work tends to contradict this, with people exhibiting more fearful avoidance behaviours.

Finally, Jim's statement of 'we have all got to get along' implies that the spatial community of the street holds a bind that forces civility, and that his customers (with whom he has to empathies with in the confines of his shop) pick up on a nuisance issue to hide the wider contextual stigma. Therefore, the orders of the street, the business in which he works, and his duty as a law-abiding citizen to protect the interests of the worker who was assaulted (comment 2, box 6), conflict and affect his behaviour in space. His confrontational approach, mentioned earlier (of sex workers standing in doorways, contravening street 
orders), is perhaps a way of encouraging order and cohesion in their coexistence (Matthews, 1993).

Furthermore, although, interestingly, not explicitly referred to as positive impacts of the parlour presence by non-sex worker participants, local business workers also casually discussed sex workers/clients coming into shops to buy items. This was reinforced in Blackpool Gazette's (2011) referral to on-street sex workers attracting clients to stay in local hotels, and the mutually-beneficial relationships with local taxi firms discussed by sex workers interviewed - drivers are tipped if they bring potential clients to the parlours.

\section{Tensions between real and perceived impacts}

Juxtaposed with, and further complicating, ambivalence towards the parlours is the masquerading of other agendas when outlining impacts. Some participants did not specifically refer to any tangible evidence of, for example, impingement on public space use, but assumptions were made about the wider societal implications of these based on stereotypes and the media. An example often cited was the potential corruption of children. Misconceptions and confusion surrounding the regulation and legal position of the parlours (and prostitution more generally) also affected impact depictions.

Whereas interviews with police officers and Councillors revealed crime rates were not especially prominent compared to other areas in Blackpool, residents often described Central Drive in particular as 'unsafe', with high crime rates and 'drug users on every corner'. Many participants, such as Janet (40: Resident on Central Drive), freely admitted that they never 
witnessed sex workers on-street, yet later made statements such as '(they) lurk at the end of the street by the cash machine (a street corner)'; indicating that this is either secondary information or reverting to stereotypes about street-workers.

It is arguable that the reason respondents conflate prostitution with such issues is because they do not know how to deal with ambiguous and ambivalent feelings towards prostitution itself; thus they move to stereotypes to feel more stable or knowledgeable about the anomalous presence (Sibley, 1995). The line between real and perceived is therefore blurred, which moral panics and media constructions perpetuate.

The conflation of parlour visibility and nuisance effects with the corruption of the innocent was also evidence of masqueraded moral beliefs/fears about the sexualization of society. This was particularly noted in conversations with Council Officers, alluding to children several times when discussing 'anti-sleaze' campaigns surrounding the visibility of the parlours, their 'sexual paraphernalia' and 'harms'. The term 'sleaze' was used as a catch-all term for anything to do with the parlours, without much definition as to what was meant exactly by this term, or how it translated to children - aside from reference to the cartoon pictures of 'scantily-clad women' which are sometimes present. Again, the prominent focus on the optical is clear here and is directly linked to the undefined 'harms' and disorder that the parlours supposedly cause.

These definitions were similarly absent, and contradictory, when talking to residents: John (55: Resident by Central Drive and Worker in both areas) expressed that sex premises could be 'more discreet' (rather than removed) due to wanting to avoid having premature sex education conversations with his children. However, despite 'walking past parlours quite regularly', 
these conversations had never taken place. Some participants also exhibited concerns about being mistaken for sex workers/clients in the areas, but rarely had this happened (only one female participant reported this). Comments suggesting that events, such as raids, are 'always in the Gazette' in their eyes add validity to the reality of the impacts, even if un-witnessed personally.

The scapegoating of parlours as having nuisance effects on the surrounding area was also masquerading wider disappointment with Blackpool Council, and was influenced by the inconsistent regulation and management of the parlours by the Council and police. Participants complained vehemently about how the Council had 'turned their back' on localities such as Central Drive (Betty 76: Resident on Central Drive). It was often during these conversations that perceived secondary impacts of the parlours were brought up - such as 'the Council ignore the druggies that hang around near the parlours' (Betty, 78: Resident on Central Drive).

Similarly, parlour regulation was discussed by the local Council and police as a 'balancing act' between law and order; to sit firmly on the boundary between adhering to the law, yet protecting both sex workers' and residents' interests. Inconsistencies in policing -'one minute they are raiding them, the next they are concentrating on something else' (Mandy, 53: Worker by Cookson Street) - and periods of Council ‘clean-ups' before quietening down again generate a lack of understanding of the legal stance of the parlours and exacerbate stereotypical assumptions being made.

Finally, this last discussion of Blackpool's localized regulation strategies highlights another important influential factor: Blackpool's reputation and identity. Blackpool is notoriously a 
leisure and pleasure town and this heightens ambivalence felt towards the parlours' place in the socio-spatial fabric. Being considerate of the town norms is therefore just as important as unpicking community heterogeneity and fluidity regarding impact discourses. Comments such as 'it is no surprise' (Police Officer, 2011) that Blackpool has a varied sexual landscape indicate that the parlours' place in local socio-spatial fabrics is influenced by the leisure and pleasure environment they are situated in, and further complicates reports of impact.

\section{'It's different every day': the multiple roles of parlours in the geographies of everyday life}

The fluidity of impact is (re)created by the multiple roles that parlours have in everyday sociospatial landscapes. Between the various scales of community and its orders, these roles fluctuate, overlap and are sometimes conflicting. Firstly, using the dirt/disgust rhetoric displayed, the parlours represent a moral yardstick for deviance/immorality (Hubbard and Sanders, 2003) and a method of hierarchizing this, depending on the type of sex work and the scale of community focus. Secondly, parlours are depicted as everyday entertainment; watching them is described by one participant as being 'better than daytime television' during the mundane hours of work. Thirdly, several participants (especially from other businesses) outlined the parlours as a conversation starter with customers and a way to build rapport or cohesion. Fourthly, living and/or working next to parlours promoted self-pride; either from the 'somebody's got to live here' notion, or because local people are seen as the educators of outsiders about spaces of sex work: 'I get asked what it's like all the time'. Finally - although this is not an exhaustive list - sex workers were just other members of the neighbourhood, to be 
chatted to just like any other. Laura and Cindy (sex workers: Central Drive area) stated that talking to the community and telling them they are 'just a business' (Cindy) was 'very important' as 'many residents believe they don't pay for things'.

Therefore, the fluctuation between socio-spatial contexts parallels fluctuation in roles and impacts of the parlours. The notion that sex work is solely responsible for the decay of communities does not take this fluctuation into account, or the complex web of communities that overlap in terms of order, power and subsequent visibility of stigma in the public sphere. Individuals apply their sense of community in different ways under different circumstances (Hoggett, 1997) and levels of acceptability of a (stigmatized) group based on the norms of the community vary depending on this role. Differentiations between, for example, the two street areas highlight the need to take into account the diversity within and between communities and local geography (dis)order when evaluating impact.

Similarly, the often homogeneously-negative impact discourses associated with sex work should not even just be shown the other side of the coin (positive); rather, impact should be seen as a diffuse, fluid and ambiguous concept that falls on a spectrum of spatial and temporal characteristics, and potency in influencing everyday life. The fact that some residents simply chat to sex workers as neighbours, or discuss no difference between their presence and, say, the local pub, is rarely outlined in community consultations.

The multiple roles and the fluidity of impact thus keep spaces of sex work in perpetually-liminal socio-spatial positions; they are never fully excluded or fully integrated (Goffman, 1963). This 
is something that is particularly reinforced when considering the 'balancing act' described by the local Council and police; parlours are tolerated, not accepted, but are also not fully excluded.

\section{Conclusion}

This paper has argued that the impacts of massage parlours on residential communities should be understood not as spatially and temporally fixed into homogeneously negative categories, but as a fluid spectrum that is context-dependent. This context includes the various multi-scaled community norms, orders and boundaries existing, alongside the socio-spatial characteristics of the parlours. The importance of understanding impact more in the concept of banal roles in everyday life, as opposed to reactionary community complaints, has also been demonstrated.

This paper has deliberately focused on issues of stigma and place, as these were the key frameworks offered by the narratives. While it is recognized that issues of class and status may also have an important bearing on attitudes, these did not emerge strongly from the narratives provided, and are thus not pursued here. Future research in areas with more of a complex socioeconomic profile may not complement these findings entirely, but this (re)emphasizes the importance of considering localized intricate community relations when making judgements on a particular (especially stigmatized) aspect of its dynamic.

While acknowledging the specificity of the UK context, these findings have several benefits to sex work research and regulatory policy. Firstly, consulting only the most vocal members of communities excludes more conciliatory viewpoints, such as sex workers; many of whom live and work in the local area. Therefore, not only are consultations not representative of a wide 
range of participants, but they are missing key sides to the debate. The mainstreaming of sex worker voices in community consultations would therefore potentially draw on some of the benefits noted by other localities that have legalized or decriminalized establishments, whereby sex workers have more rights to report crime (eg exploitation from parlour owners) without fear of prosecution or other partnered consequences. Appreciating the complexity of community and seeking to understand its multi-scaled, multi-faceted characteristics - is essential in evaluating impact and creating a nuanced picture. The localized ethnographic lens revealed that residents' perceptions of the parlours - and subsequent socio-spatial behaviours - fluctuated because of (conflicted) loyalties to various community ties.

Refraining from just seeing 'massage parlours' as possessing homogeneous characteristics is also important. Although ambivalence from residents was shown throughout, there were slight variations in the deployment of socio-spatial behaviours from residents as a result of these impacts. This was due to differences in massage parlour/sex worker integration into everyday social spheres, the parlours' behaviour and visibility as individual businesses, and the surrounding socio-spatial fabrics of the streets. Secondly, therefore, legal and regulatory policy should be considerate of the fact that there is variation within as well as between types of sex work. Parlours have a variety of roles in residents' everyday lives, and in the socio-economic fabric of the local area, which fluctuate frequently - voyeuristically watching and/or judging their activities as a space of desire/disgust is only one of them. Regulators also need to be more aware that the politics of sex work (in)visibility in the streetscape are potentially more complex than the common narrative of linking increased exposure with disorder - and are made more so in this case study by the heterogeneity of parlour characteristics and the fluidity of these over 
time. The narratives also highlighted potential tensions between what local authorities wish to govern, and what residents believed to be the most beneficial for their locality.

Finally, the assumption that research on sex work requires a specific outcome - such as rescuing the women - has been opposed in this case. Negotiating better relations between sex workers, local residents and the Council/gatekeepers is likely to have more of a positive impact for all concerned, as opposed to making stereotypical judgements, and assuming a dramatic adaptation (such as closure) is necessary or desired by those in the vicinity.

\section{Notes}

1. Residents who live permanently within these locations (22), residents who live $<0.5$ miles away but experience the areas daily (19), and individuals who work in these zones but do not necessarily live there (12) were interviewed. The selection was to explore if degree of choice affects perceptions (be that route choice to a place of employment, or a more permanent choice of where to live).

2. Only images/names of parlours have been cited whereby they have a confident on-street and online presence. All participant names are pseudonyms. A more detailed description of the methods and ethics can be found in my doctoral thesis (see Cooper 2014). 


\section{References}

Atkins M and Laing M (2012) Walking the beat and doing business: exploring spaces of male sex work and public sex. Sexualities 15(5/6): 622-643

Benson C and Matthews R (2000) Police and prostitution: vice squads in Britain. In: Weitzer, R. (ed) Sex for Sale. London: Routledge, pp. 245-264.

Blackpool Council (2011) Small Area Statistics. Available at https://www.blackpool.gov.uk/Atlas/WardAtlas/abtlas.html (accessed 20 November 2014)

Blackpool Gazette (2011) Blackpool's sex trade: reality of life on the streets. Available at http://www.blackpoolgazette.co.uk/news/local/blackpool-s-sex-trade-reality-of-life-on-thestreets-1-3975922 (accessed 20 November 2014)

Blackpool Gazette (2013) Filthy massage parlour closed. Available at http://www.blackpoolgazette.co.uk/news/crime/filthy-massage-parlour-closed-1-5359495. (accessed 22 November 2014)

Brents B and Sanders T (2010) Mainstreaming the sex industry: economic inclusion and social ambivalence. Journal of Law and Society 37(1): 40-60

Brooks-Gordon B (2006) The Price of Sex: Prostitution, Policy and Society. Cullompton: Willan Publishing

Cooper E (2008) Moral and immoral spaces: the impacts of the social construction of space on attitudes towards off-street sex work in Blackpool. Undergraduate Dissertation: Lancaster University

Cooper E (2014) 'It's better than daytime television': questioning the impacts of Blackpool's massage parlours on people and place. Doctoral Thesis: Lancaster University

Crofts P (2010) Brothels: outlaws or citizens? International Journal of Law in Context 6(2): 151-166

Desyllas M (2013) Representations of sex workers' needs and aspirations: a case for arts-based research. Sexualities 16(7): 772-787

Edwards M (2010) Gender, social disorganization theory, and the locations of sexually orientated businesses. Deviant Behavior 31: 135-158

Goffman E (1963) Stigma: Notes on the Management of Spoiled Identity. New Jersey: Prentice-Hall

Hoggett P (1997) Contested Communities: Experiences, Struggles, Policies. Bristol: The Policy Press

Hubbard P (1997) Red-light districts and Toleration Zones: geographies of female street prostitution in England and Wales. Area 29(2): 129-40 
Hubbard P (2000) Desire/disgust: mapping the contours of heterosexuality. Progress in Human Geography 24(2): 191-217

Hubbard P and Sanders T (2003) Making space for sex work: female street prostitution and the production of urban space. International Journal of Urban and Regional Research 27(1): 75-89

Hubbard P and Prior J (2013) Out of sight, out of mind? Prostitution policy and the health, wellbeing and safety of home-based sex workers. Critical Social Policy 33(1): 140-159

Hubbard P, Boydell S, Crofts P, Prior J and Searle G (2013) Noxious neighbours? Interrogating the impacts of sex premises in residential areas. Environment and Planning A 45: 126-141

Ibbitson M (2002) Out of the sauna: sexual health promotion with 'off-street' sex workers. J Epidemiol Community Health 56: 903-904

Jana S, Dey B, Reza-Paul S and Steen R (2013) Combating human trafficking in the sex trade: can sex workers do it better? Journal of Public Health 36(4): 622-628

Kantola J and Squires J (2004) Discourses surrounding prostitution policy in the UK. European Journal of Women's Studies 11(1): 77-101

Kingston S (2013) Prostitution in the Community: Attitudes, Actions and Resistance. Abingdon: Routledge

Krusi A, Chettiar J, Ridgeway A, Abbott J, Strathdee S and Shannon K (2012) Negotiating safety and sexual risk reduction with clients in unsanctioned quasi-brothels: a qualitative study. $\mathrm{Am} J$ Public Health 102(6): 1154-1159

Lancashire County Council (2012). Blackpool Unitary Profile http://www.lancashire.gov.uk/corporate/web/?siteid=6233\&pageid $=39644 \& \mathrm{e}=\mathrm{e}$

Lancashire Telegraph (2013) Council chief says Blackburn massage parlour absolutely unacceptable. Available at

http://www.lancashiretelegraph.co.uk/news/10736863.Council_chief_says_Blackburn_massage parlour absolutely unacceptable /? ref=rss (accessed 31 March 2015)

Liverpool Echo (2014) Rubbed up the wrong way - massage parlour should not be next to Liverpool church and school say residents. Available at http://www.liverpoolecho.co.uk/news/liverpoolnews/fury-over-liverpool-massage-parlour-7416928 (accessed 31 March 2015)

Matthews R (1993) Kerb-crawling, prostitution and multi-agency policing. Police Research Group Crime Prevention Unit Series Paper No. 43 London: Home Office Police Department

Mathieu L (2011) Neighbors' anxieties against prostitutes' fears: ambivalence and repression in the policing of street prostitution in France. Emotion, Space and Society 4: 113-120 
O’Neill M, Campbell R, Hubbard P, Pitcher J, and Scoular J (2008) Street Sex Work, Contingent Communities and Degrees of Tolerance. Crime, Media, Culture 4(1): 73-93

Prior J and Crofts P (2012) Effects of sex premises on neighbourhoods: residents, local planning and the geographies of a controversial land use. New Zealand Geographer 68(2): 130-140

Sagar T and Jones D (2012). Priorities for the minority? Street-based sex work and Partnerships and Communities Together (PACT). Criminology and Criminal Justice 13(4): 1-15

Sanchez L (2004) The global e-rotic subject, the ban, and the prostitute-free zone: sex work and the theory of differential exclusion. Environment and Planning D, Society and Space 22: 961-883

Sanders T (2005) Sex work: A Risky Business. Willan Publishing: Devon

Sanders T (2006) Behind the personal ads: indoor sex markets in Britain. In: Campbell R and O'Neill M (eds) Sex Work Now. Collumpton: Willan Publishing, pp. 92-115

Sanders T (2007) No room for a regulated market? The implications of the coordinated prostitution strategy for the indoor sex industries. Community Safety Journal 6(1): 34-44

Sanders T (2008) Selling sex in the shadow economy. International Journal of Social Economics. 35(1): 704-716

Sanders T and Soothill K (2011) The policing of pleasure: 'What kind of police service do we want? The Police Journal 84(2): 110-124

Shaver F (2005) Sex work research: methodological and ethical challenges. Journal of Interpersonal Violence 20(3): 296-319

Sibley D (1995) Geographies of Exclusion: Society and Difference in the West. London: Routledge

Smith D (2000) Moral Geographies: Ethics in a World of Difference. Edinburgh University Press

Soothill K (2004) Parlour games: the value of an Internet site providing punters' views of massage parlours. The Police Journal: Theory, Practice and Principles 77(1): 43-53

Spector J (2006) (ed.) Prostitution and Pornography: Philosophical Debate about the Sex Industry. Stanford: Stanford University Press

Strysick M (2002) The Politics of Community. Davies Group Publishers

Symanski R (1981) The Immoral Landscape: Female Prostitution in Western Societies. Toronto: Butterworths

The Guardian (2009) Prostitution and trafficking - the anatomy of a moral panic. Available at http://www.theguardian.com/uk/2009/oct/20/trafficking-numbers-women-exaggerated (Accessed 02 April 2015) 
The Guardian (2013) Soho police raids show why sex workers live in fear of being 'rescued'. Available at http://www.theguardian.com/commentisfree/2013/dec/11/soho-police-raids-sex-workers-feartrafficking (Accessed 02 April 2015)

Weitzer R (2005) New directions in research on prostitution. Crime, Law \& Social Change 43: 211-235

Weitzer R (2007) The social construction of sex trafficking: ideology and institutionalization of a moral crusade. Politics and Society 356: 447-475

Whittaker D and Hart G (1996) Research note: Managing risks: the social organization of indoor sex work. Sociology of Health \& Illness 18(3): 399-414

\section{Figures}

Figure 1 - Cookson Street.

Figure 2 - Central Drive. 